\title{
IMPACTO DA ALTERAÇÃO DO RATING SOBERANO NO CUSTO DE CAPITAL DE EMPRESAS BRASILEIRAS, 2005-2015
}

\author{
CHANGE OF SOVEREIGN RATING AND IT'S IMPACT IN COST OF CAPITAL OF BRAZILIAN \\ COMPANIES, 2005-2015
}

João Victor Soares Maciel

Faculdade IBMEC de Minas Gerais

Belo Horizonte, MG, Brasil

E-mail: joaovictorsm10@gmail.com

Marcos Antônio de Camargos

Professor Adjunto Faculdade IBMEC de Minas Gerais e CEPEAD-UFMG

Belo Horizonte, MG, Brasil

E-mail: marcos.camargos@ibmec.edu.br

\section{RESUMO}

Nos últimos 15 anos o Brasil passou por altos e baixos no que se refere à sua classificação de risco (risco soberano). A obtenção e manutenção do grau de investimento são importantes tanto para empresas, quanto para países. Dentre os benefícios que um upgrade do rating pode trazer para as empresas pode-se destacar a potencial redução em seu custo de capital. O objetivo deste trabalho é identificar se a alteração da classificação do risco soberano impacta no custo de capital das empresas brasileiras listadas na BM\&FBovespa entre 2005 e 2015. Em termos metodológicos, trata-se de uma pesquisa descritiva, com enfoque quantitativo, elaborada com dados secundários anuais de uma amostra de 20 empresas, que fez uso de um modelo de regressão múltipla com dados em painel dinâmico. Em linhas gerais, foi constatada uma redução no custo de capital das empresas, principalmente próprio $(\mathrm{Ke})$ diante de upgrades do risco soberano do país.

Palavras-chave: Rating. Risco Soberano. Custo de Capital. Grau Especulativo e Grau de Investimento.

\section{ABSTRACT}

In the last 15 years, Brazil has experienced highs and lows in terms of its risk classification (sovereign risk). Obtaining and maintaining the degree of investment is important for both companies and countries. Among the benefits that a rating upgrade can bring to companies may be the potential reduction in their cost of capital. This paper aims to identify if the change in the sovereign risk classification impacts on the cost of capital of the Brazilian companies listed on the BM\&FBovespa between 2005 and 2015. In methodological terms, this is a descriptive research, with a quantitative approach, elaborated with secondary data Annual data from a sample of 20 companies using a multiple regression model with dynamic panel data. In general terms, there was a reduction in the cost of capital of companies, mainly equity cost $(\mathrm{Ke})$ in face of upgrades of the sovereign risk of the country.

Keywords: Rating. Sovereign Risk. Cost of Capital. Speculative Degree and Investment Grade.

Data de submissão: 25 de agosto de 2017.

Data de aprovação: 9 de julho de 2018. 


\section{INTRODUÇÃO}

As empresas do mundo inteiro vêm vivenciando um cenário de uma maior integração econômica e financeira, decorrente da intensificação do comércio internacional, enfraquecimento das fronteiras nacionais, entre outras mudanças, nas últimas duas décadas. De um lado, tem-se um fluxo crescente de investidores, que cada vez mais buscam investimentos fora dos seus países de origem, incorrendo em maior risco na busca de investimentos com maior rentabilidade. De outro, governos que devido aos elevados gastos se veem obrigados a emitir títulos de dívida, competindo pelos recursos no mercado financeiro com as empresas, que por sua vez dependem dos recursos captados para financiar suas atividades.

Esse é o cenário com que se depara o investidor, que para realizar investimentos de maneira segura, deve conhecer ou dispor de informações para fazer uma avaliação correta dos riscos envolvidos na operação. A despeito dos avanços observados no campo da governança corporativa, no Brasil e o mundo, ainda é notória a assimetria de informação existente entre empresas emissoras e os investidores, o que gera, por um lado, aumento do risco e, por consequência, aumento do custo para o levantamento das informações necessárias para a tomada de decisão sobre o investimento, e por outro, onera as empresas, que no intuito de reduzir essa assimetria, se veem obrigadas a divulgar cada vez mais informações ao mercado.

Nesse cenário, as agências de classificação de risco (rating) desempenham importante papel, ao avaliar o grau de risco de crédito dos agentes emissores de títulos (empresas e países), no que se refere à sua capacidade de geração de fluxos de caixa suficientes para que não ocorra o default, situação na qual o emissor não consegue mais fazer frente ao fluxo de pagamentos, seja dos juros, seja do principal de suas dívidas. Essa classificação geralmente é expressa na forma de letras (categorias), dentro de uma escala estabelecida por cada agência. $O$ foco dessas instituições é analisar companhias ou países e emitir um rating (nota), que mostra a capacidade de pagamento, assim como a probabilidade de inadimplência do emissor (ASSAF NETO, 2014).

Poon e Chan (2008) salientam que o rating de crédito serve para duas finalidades: (1) certifica a condição financeira existente de uma empresa aos investidores (rating inicial); e, (2) sinaliza uma mudança da condição financeira prevalecente de uma empresa (downgrades ou upgrades no rating).

Segundo Cavalcante, Misumi e Rudge (2009), os investidores usam o rating para: (1) auxiliar na tomada de decisão e precificação do risco de crédito em títulos de renda fixa; (2) limitar seus parâmetros de investimento; e, (3) nortear a expansão dos seus horizontes para novos mercados ou títulos. Na outra ponta, o rating ajuda os emissores de dívida na obtenção de acesso estável e flexível às fontes de capital no mercado financeiro. Assim, o rating cumpre as funções de formar, junto aos investidores, opinião sobre a qualidade dos títulos emitidos por determinada empresa ou país e servir de parâmetro para a determinação das taxas de juros que esses papéis oferecem (SOARES, COUTINHO e CAMARGOS, 2012).

Além de emitir uma nota para alguma companhia específica, as agências também classificam o risco de crédito de um país. Conforme destaca a Agência Moody's (1999), os ratings são chamados de corporativos, no caso de empresas, e de soberanos, no caso de países. A avaliação do risco soberano deve julgar não somente a capacidade de pagamento dos governos, mas principalmente sua disposição de pagar, tornando assim a análise mais complexa do que a avaliação do risco de uma empresa (MOODY'S, 1999). A capacidade de pagamento de um governo pode ser afetada pela falta de mecanismos para garantir o 
cumprimento dos termos acordados de sua dívida, além disso, a disposição e a capacidade de pagamento são fortemente influenciadas por decisões político-ideológicas.

Três grandes agências de classificação de risco se destacam atualmente no mercado financeiro internacional, no fornecimento de rating ao mercado, Moody's, Standard \& Poor's e Fitch. Segundo a Standard \& Poor's (2004), apesar das diferentes grades de classificação, o que há em comum entre elas é a segregação dessa grade em duas categorias: (1) grau de investimento: condição de baixo risco de crédito conferida a um país ou empresa, que apresenta garantias e reduzida vulnerabilidade a fatores de perturbação externos. Ou seja, nível de inadimplência de baixo para mediano; e, (2) grau especulativo: condição na qual o emissor apresenta alguma vulnerabilidade a fatores de perturbação externos que aumenta o risco de default.

A obtenção e manutenção do grau de investimento são importantes tanto para empresas, quanto para países. Para as empresas podem proporcionar a ampliação: do mercado de atuação, do volume de vendas, do volume de captação de capital externo, além da redução do custo do capital. E para o país, podem proporcionar o aumento da credibilidade coletiva do país e seus empresários, facilitar e reduzir as taxas de juros em captações de recursos no mercado internacional. Vale destacar que, devido a cláusulas contratuais, boa parte dos investidores internacionais só pode adquirir títulos dos países classificados como grau de investimento, reforçando a importância.

A obtenção do grau de investimento por parte da economia brasileira foi de grande destaque por parte dos governantes, mercado financeiro e empresários à época em que foi conferida, no final de 2008 pela Standard \& Poor's e Fitch e em setembro de 2009 pela Moody's. Infelizmente o ambiente político instável conjugado com decisões equivocadas por parte do governo federal levou a uma degradação dos principais indicadores macroeconômicos da economia brasileira a partir de 2010, culminando na perda do grau de investimento em 2015 da Standard \& Poor's e Fitch, e em 2016 pela Moody's.

Inserido nesse contexto, o objetivo deste trabalho é identificar se alteração da classificação de risco do país (risco soberano) impactou no custo de capital das empresas brasileiras listadas na BM\&FBovespa, considerando o período de 2005 a 2015. Ou seja, pretende-se avaliar quais os efeitos que alterações no rating soberano brasileiro realizadas por duas das três principais agências de classificação de risco (S\&P e Fitch), seja majoração (upgrade) ou diminuição (downgrade), tem sobre o custo de capital das empresas brasileiras.

$\mathrm{O}$ artigo tem a seguinte estrutura, após essa introdução, a seção 2 apresenta o referencial teórico de suporte à pesquisa empírica. A metodologia e os resultados são apresentados nas seções 3 e 4 , respectivamente. Encerra-se com as considerações finais na seção 5 , seguidas das referências. 


\section{REFERENCIAL TEÓRICO}

\section{Rating}

O rating é uma ferramenta relevante na tomada de decisão sobre investimentos em títulos de crédito, tanto de empresas, quanto do governo (países). Murcia, Murcia e Borba (2014) destacam a importância dele para vários agentes da economia: (a) empresas emissoras: balizador da taxa de juros / custo de capital; (b) investidores: avaliação da capacidade de pagamento dos emissores; (c) reguladores: economia de recursos direcionados à avaliação do crédito; (d) mercado: complemento dos sistemas de avaliação da capacidade de solvência. Schuermann e Jafry (2003) acrescentam que o rating é também, largamente utilizado na gestão de riscos, como na avaliação de risco de portfólios, na modelagem da estrutura a termo do prêmio de risco de crédito e na precificação de derivativos de crédito.

Segundo a Moody's (1999), rating consiste na estimativa da capacidade futura, da responsabilidade jurídica e da vontade de emissor efetuar, dentro do prazo, pagamentos do principal e juros de seus títulos de renda fixa. A classificação do risco de crédito se divide em: (a) risco soberano, conferido a países, que consiste de um indicador que expressa o risco ao qual o investidor estrangeiro está submetido ao adquirir títulos dívida emitidos pelo país, sua base é a conjuntura econômica, social e política do país emissor; (b) risco corporativo, conferido às grandes empresas, refletindo a capacidade da empresa emissora em honrar com fluxo de desembolso futuro da obrigação emitida (MOODY'S, 1999).

Para Altman, Caouette e Narayanan (1998), na determinação do rating corporativo, geralmente são levados em consideração: (a) risco do negócio: características do setor de atuação, posição competitiva, gestores, governança corporativa; e, (b) risco financeiro: características financeiras, política de financiamento, lucratividade, estrutura de capital, proteção em termos de fluxo de caixa, flexibilidade financeira. Damasceno, Artes e Minardi (2008) acrescentam que dessas categorias, o risco ligado ao setor de atuação (análise da atratividade e estabilidade da indústria na qual a empresa opera) possui o maior peso na atribuição do rating.

Gray, Mirkovic e Ragunathan (2006) salientam que, em âmbito corporativo, em termos práticos, a importância do rating está no fato de que impacta no custo da dívida da empresa, na sua estrutura de capital, bem como no potencial futuro de novas captações no mercado. Um downgrade no rating está associado à elevação do custo de capital de terceiros, pois, impacta tanto na taxa de juros que a empresa terá que pagar, quanto na tomada de decisões sobre a contratação de novos empréstimos / emissões de títulos de dívida no mercado financeiro.

Segundo Creighton, Gower e Richards (2007), por serem especialistas na obtenção e processamento da informação sobre o risco de default, a atuação das agências de rating reduzem os custos dos credores de reunir informações, facilitando as operações do mercado de títulos. Jorion, Siu e Shi (2005) acrescentam que os analistas das agências de rating têm acesso às informações confidenciais que não estão disponíveis para outros profissionais financeiros, podendo aumentar o valor dos ratings ao público.

Kliger e Sarig (2000) destacam que o processo de atribuição do rating geralmente se inicia com o emissor do título requisitando um rating, ou alternativamente a agência de rating pode entrar em contato com o emissor após o registro do novo título de dívida no órgão regulador. Chan, Edwards e Walter (2009) complementam destacando que o processo de atribuição do rating ocorre em três etapas: (1) os analistas de 
rating reúnem informações públicas disponíveis relevantes do título emitido, bem como informações privadas apresentadas pelo emissor na reunião com os gestores; (2) um comitê de rating é convocado e recomendações são feitas sobre o título emitido baseadas na metodologia estabelecida; e, (3) disseminação e publicação, na forma press release, do rating atribuído.

De acordo com Silva (2008), as três principais agências de rating que são norte-americanas, a $S \& P$, a Moody's e a Fitch, e juntas representam 90\% do mercado de emissão de ratings. O Quadro 1 apresenta as categorias e, ou níveis de classificação adotadas atualmente por estas três agências. A adição dos sinais positivo (+) e negativo (-) nos ratings de AA até CCC (S\&P e Fitch) e 1, 2 e 3 (Moody's) serve para mostrar a posição relativa do rating dentro das grandes categorias.

Quadro 1: Classificações de Rating

\begin{tabular}{|c|c|c|c|c|c|}
\hline$S \& P$ & Fitch & Moody's & $S \& P$ & Fitch & Moody's \\
\hline \multicolumn{3}{|c|}{ Grau de Investimento } & \multicolumn{3}{|c|}{ Grau Especulativo } \\
\hline AAA & AAA & Aaa & $\mathrm{BB}+$ & $\mathrm{BB}+$ & $\mathrm{Ba} 1$ \\
\hline $\mathrm{AA}+$ & $\mathrm{AA}+$ & Aa1 & BB & BB & $\mathrm{Ba} 2$ \\
\hline AA & AA & Aa2 & BB- & BB- & Ba3 \\
\hline AA- & AA- & Aa3 & $\mathrm{B}+$ & $\mathrm{B}+$ & B1 \\
\hline$A+$ & $A+$ & A1 & B & B & B2 \\
\hline A & A & A2 & B- & B- & B3 \\
\hline A- & A- & A3 & $\mathrm{CCC}+$ & $\mathrm{CCC}+$ & Caa1 \\
\hline $\mathrm{BBB}+$ & $\mathrm{BBB}+$ & Baa1 & $\mathrm{CCC}$ & $\mathrm{CCC}$ & Caa2 \\
\hline BBB & BBB & Baa2 & CCC- & CCC- & Caa3 \\
\hline \multirow[t]{5}{*}{ BBB- } & BBB- & Baa3 & $\mathrm{CC}$ & $\mathrm{CC}$ & - \\
\hline & & & C & C & - \\
\hline & & & $\mathrm{SD}^{1}$ & DDD & $\mathrm{Ca}$ \\
\hline & & & $\mathrm{D}^{2}$ & DD & C \\
\hline & & & - & D & - \\
\hline
\end{tabular}

FONTE - Adaptado de Silva (2008).

O ponto em comum na classificação dessas três agências é a segregação em duas categorias: (1) grau de investimento: condição de baixo risco de crédito conferida a um país ou empresa, que apresenta garantias e reduzida vulnerabilidade a fatores de perturbação externos. Ou seja, nível de inadimplência de baixo para mediano; e (2) grau especulativo: condição na qual o emissor apresenta alguma vulnerabilidade a fatores de perturbação externos que aumenta o risco de default, oferecendo oportunidades de ganhos altos, mas com riscos significativos de perda do investimento (SILVA, 2008). O Quadro 2 apresenta o histórico de ratings atribuídos ao Brasil entre 2004 e 2015. 
Quadro 2: Histórico do Rating Soberano do Brasil, 2004-2015

\begin{tabular}{|l|ccc|c|}
\hline ANO & S\&P & Fitch & Moody's & GRAUS \\
\hline $\mathbf{2 0 0 4}$ & BB- & BB- & B1 & Grau Especulativo \\
$\mathbf{2 0 0 5}$ & BB- & BB- & Ba3 & \\
$\mathbf{2 0 0 6}$ & BB & BB & Ba2 & \\
\hline $\mathbf{2 0 0 7}$ & BB+ & BB+ & Ba1 & \\
$\mathbf{2 0 0 8}$ & BBB- & BBB- & Ba1 & \\
$\mathbf{2 0 1 0}$ & BBB- & BBB- & Baa3 & Grau de Investimento \\
$\mathbf{2 0 1 1}$ & BBB & BBB- & Baa4 & \\
$\mathbf{2 0 1 2}$ & BBB & BBB & Baa2 & \\
$\mathbf{2 0 1 3}$ & BBB & BBB & Baa2 & \\
$\mathbf{2 0 1 4}$ & BBB- & BBB & Baa2 & Grau Especulativo \\
\hline $\mathbf{2 0 1 5}$ & BB+ & BB+ & Baa3 & \\
\hline
\end{tabular}

FONTE - Compilado pelos autores a partir de dados extraídos do site www.tesouro.fazenda.gov.br

Dos 12 anos apresentados no Quadro 2, em oito a economia brasileira foi classificada com grau de investimento e quatro como grau especulativo.

\section{Estrutura e Custo de Capital}

A teoria de Finanças não apresenta de maneira objetiva como os gestores definem o endividamento das empresas, e a literatura empírica ainda não conseguiu chegar a uma conclusão sobre o tema. Segundo Eid Jr. (1996), provavelmente, o campo que gera mais controvérsia dentro da teoria de Finanças é o estudo da estrutura e do custo do capital das empresas.

A estrutura de capital é conceituada como a combinação entre o volume de recursos próprios e de terceiros utilizados por uma empresa para financiar seus investimentos (ROSS et al., 2015). A definição da estrutura de capital perfeita é uma das áreas mais complexas da tomada de decisão financeira devido ao seu inter-relacionamento com outras variáveis financeiras de decisão (DAMODARAN, 2004).

A estrutura de capital reflete assim, as decisões sobre as fontes de financiamento da empresa. Para captar recursos de terceiros, a empresa pode se alavancar, contratando empréstimos, financiamentos ou emissões de títulos. Para captar recursos próprios, ou seja, se capitalizar (aumentar o seu patrimônio líquido), ela pode receber aporte de recursos dos atuais sócios ou de novos sócios (abertura de capital) ou reter parte do seu lucro.

Independente da fonte de recurso, o certo é que a empresa terá que arcar com um custo para obter e manter estes recursos. Geralmente o custo de capital próprio é superior ao custo de capital de terceiros, devido ao fato de os acionistas assumirem a maior parcela de risco inerente a qualquer atividade empresarial. Enquanto o capital de terceiros tem sua remuneração, prazo de disponibilidades e garantias fixadas em contrato, o capital próprio não desfruta dessas possibilidades (ASSAF NETO, 2014). 
Conforme salienta Damodaran (2004), tanto proprietários (acionistas), quanto credores aportam recursos na empresa esperando obter retorno. $O$ retorno esperado para os primeiros inclui um prêmio para o risco do patrimônio líquido no investimento, sendo denominado de custo de capital próprio (Ke). Similarmente, o retorno esperado pelos credores inclui um prêmio para o risco de não recebimento dos juros e /ou principal, sendo denominado de custo do capital de terceiros $(K d)$. $O K d$ pode ser calculado internamente pela ponderação do custo das suas dívidas (de curto e longo prazo) com o seu respectivo peso / valor. Uma forma mais prática e de grande uso nas pesquisas acadêmicas é o custo médio da dívida, obtido a partir de dados extraídos das demonstrações financeiras da empresa, divisão das despesas financeiras pelo endividamento oneroso total. Independente da forma de cálculo deve-se sempre levar em consideração o benefício fiscal gerado pela dedução das despesas financeiras do lucro tributável, ocasionando economia de imposto de renda.

Dentre as diversas formas para se determinar o custo do capital próprio, segundo Copeland, Koller e Murrin (2002), a metodologia mais utilizada por pesquisadores é o Capital Asset Pricing Model (CAPM). Tratase de um modelo que relaciona o retorno (ou custo do capital) com o nível de risco apresentado por um ativo ou empresa, determinado pelo coeficiente beta. A fórmula para o cálculo de custo de capital próprio (Ke) utilizando o CAPM é:

$$
K e=R_{f}+\beta_{a}\left(R_{m}-R_{f}\right)
$$

Na qual: Ke: custo do capital próprio; $R_{f}$ : taxa livre de Risco; $\beta_{a}$ : coeficiente beta do ativo; e $R_{m}$ : taxa de retorno esperada da carteira de mercado.

Segundo Ross et al. (2015), o coeficiente beta exprime o risco sistemático de um ativo, ou seja, mostra como o retorno em excesso de uma ação se move em relação ao retorno em excesso do mercado todo, sendo identificado com o parâmetro angular na reta de regressão linear, mostrando assim, o risco que um ativo agrega à carteira de mercado pela sua covariância com essa carteira, padronizado (dividido) pela variância da carteira de mercado, conforme equação 2 .

$$
\beta_{a}=\frac{\operatorname{Cov}\left(R_{a} R_{m}\right)}{\sigma_{R_{m}}^{2}}
$$

Na qual: $\beta_{a}$ : coeficiente beta do ativo; $\operatorname{Cov}\left(R_{a} R_{m}\right)$ : covariância do retorno do ativo com o retorno da carteira de mercado e $\sigma_{R_{m}}^{2}$ : a variância da carteira de mercado.

A taxa livre de risco deve ser um ativo em que o investidor conhece com exatidão os retornos esperados. É considerado um ativo sem risco aquele que possui risco mínimo de default, ou seja, quase não há risco de a instituição emissora não honrar o compromisso (DAMODARAN, 2004).

O resultado da subtração Rm - Rf, denominado de prêmio de risco do mercado, é o retorno extra que seria exigido por transferir recursos de um investimento sem risco para um investimento com risco. Neste sentido, multiplicando este prêmio de risco pelo beta que é a medida de risco dos retornos de um ativo em relação aos retornos de mercado, obtém-se o resultado de qual a taxa deverá ser aceita para assumir a variação do risco de mercado e a o risco não diversificável deste ativo. 
Como as empresas se financiam com recursos próprios e de terceiros, o custo de capital é estabelecido pelas condições com que a empresa obtém seus recursos financeiros no mercado de capitais, sendo geralmente determinado por uma média dos custos de oportunidade do capital próprio (acionistas) e capital de terceiros (credores), ponderados pelas respectivas proporções utilizadas de capital, e líquidos do imposto de renda (ASSAF NETO, LIMA e ARAÚJO, 2008), conhecido como Custo Médio Ponderado de Capital (CMPC) ou Weighted Average Cost of Capital (WACC), conforme equação 3:

$$
W A C C=K d \cdot(1-T) \cdot \frac{D}{D+E}+K e \cdot \frac{E}{D+E}
$$

$\mathrm{Na}$ qual: $K d$ : custo de capital de terceiros; Ke: custo de capital próprio; D: dívida onerosa total (debts); E: patrimônio líquido (equities); $D$ / $(D+E)$ : proporção ou peso das dívidas; $E$ / $(D+E)$ : proporção ou peso dos recursos próprios na estrutura de capital e $T$ : a alíquota de imposto de renda.

Em termos práticos o WACC representa as expectativas mínimas de remuneração das diversas fontes de financiamento (próprias e de terceiros) lastreando suas operações. Ele é essencial para a tomada de decisões financeiras, ao representar o retorno médio exigido para toda a empresa, que pode ser usado como uma medida de avaliação da atratividade econômica de um investimento, de referência para a análise de desempenho e viabilidade operacional e de definição de uma estrutura ótima de capital (ASSAF NETO, LIMA e ARAÚJO, 2008). Além disso, é a taxa utilizada para de descapitalizar fluxos de caixa projetados das empresas em técnicas de valuation. 


\section{Revisão da Literatura Empírica}

O Quadro 3 apresenta uma síntese dos principais trabalhos realizados sobre classificação de risco de empresas brasileiras.

Quadro 3: Evidências empíricas na literatura nacional

\begin{tabular}{|c|c|c|c|}
\hline $\begin{array}{l}\text { Autores } \\
\text { IAno }\end{array}$ & Amostra & $\begin{array}{l}\text { Modelo/ } \\
\text { Período }\end{array}$ & Conclusões \\
\hline $\begin{array}{c}\text { Klotzle, et al. } \\
\quad(2016)\end{array}$ & $\begin{array}{c}\text { Nove } \\
\text { empresas } \\
\text { públicas }\end{array}$ & $\begin{array}{l}\text { Estudo de } \\
\text { Evento } \\
\text { (2002 a } \\
2014)\end{array}$ & $\begin{array}{l}\text { Os eventos negativos (downgrades no risco soberano) proporcionaram, } \\
\text { com significância estatística, um impacto negativo no preço desses ativos } \\
\text { e os eventos positivos (upgrades) não impactaram, com significância } \\
\text { estatística, positivamente o comportamento das ações. O retorno anormal } \\
\text { médio acumulado apontou que os anúncios de downgrade impactaram de } \\
\text { forma mais intensa o mercado frente aos anúncios de upgrade, mesmo } \\
\text { que no sentido oposto ao inicialmente esperado. }\end{array}$ \\
\hline $\begin{array}{c}\text { Soares, } \\
\text { Coutinho e } \\
\text { Camargos } \\
(2012)\end{array}$ & $\begin{array}{c}72 \\
\text { empresas }\end{array}$ & $\begin{array}{l}\text { Modelo Logit } \\
\text { Ordenado } \\
(2010)\end{array}$ & $\begin{array}{l}\text { Um pequeno número de variáveis pode explicar o rating de crédito de uma } \\
\text { empresa, mais precisamente, governança corporativa, tamanho dos ativos } \\
\text { e índice de cobertura de juros. Isso quer dizer que, na regressão proposta, } \\
\text { a baixa divulgação de informações ao mercado, o maior porte da empresa } \\
\text { e um maior potencial de cobertura de juros contribuem para redução do } \\
\text { risco de crédito e aumento do rating. }\end{array}$ \\
\hline $\begin{array}{c}\text { Almeida } \\
(2010)\end{array}$ & $\begin{array}{c}\text { Índice } \\
\text { Ibovespa e } \\
\text { EMBI }\end{array}$ & $\begin{array}{c}\text { Teste T } \\
\text { (Jan/2001 a } \\
\text { Jul/2010) }\end{array}$ & $\begin{array}{l}\text { Os agentes de mercado conseguem antecipar as notícias ruins antes da } \\
\text { divulgação das mesmas pelas agências em vista do dinamismo e } \\
\text { abrangência dos vários canais de comunicação públicos e privado } \\
\text { disponível no mercado financeiro, sinalizando para uma eficiência } \\
\text { semiforte. Os retornos dos ativos refletem não apenas o histórico de } \\
\text { comportamento de retornos, mas também todas as informações } \\
\text { disponíveis no mercado. }\end{array}$ \\
\hline $\begin{array}{l}\text { Brito, Assaf } \\
\text { Neto e Corrar } \\
\quad(2009)\end{array}$ & $\begin{array}{c}66 \\
\text { empresas }\end{array}$ & $\begin{array}{l}\text { Regressão } \\
\text { Múltipla } \\
\text { (1995 a } \\
2006)\end{array}$ & $\begin{array}{l}\text { O sistema de classificação desenvolvido captura o risco das companhias } \\
\text { previamente à ocorrência do default, uma vez que a maior parte dessas } \\
\text { empresas é classificada nos piores níveis de rating ou apresenta } \\
\text { migrações de risco para ratings inferiores (downgrades) nos anos que } \\
\text { precederam o default. }\end{array}$ \\
\hline $\begin{array}{c}\text { Damasceno, } \\
\text { Artes e } \\
\text { Minardi } \\
(2008)\end{array}$ & $\begin{array}{c}36 \\
\text { empresas }\end{array}$ & $\begin{array}{c}\text { Dados em } \\
\text { Painel (2000 } \\
\text { a 2005) }\end{array}$ & $\begin{array}{l}\text { A Standard \& Poor's tem sido, entre os anos de } 2000 \text { e } 2005 \text {, mais } \\
\text { restritiva em suas análises de crédito para empresas brasileiras não- } \\
\text { financeiras, ou seja, não foram encontrados indícios de que uma empresa } \\
\text { com os mesmos indicadores contábeis ao longo do tempo receba, } \\
\text { atualmente, uma avaliação de risco de crédito pior do que a atribuída em } \\
\text { anos anteriores. }\end{array}$ \\
\hline $\begin{array}{c}\text { Brito, Corrar, } \\
\text { Batistella } \\
(2002)\end{array}$ & $\begin{array}{c}466 \\
\text { empresas }\end{array}$ & $\begin{array}{c}\text { Dados em } \\
\text { Painel (1998 } \\
\text { a 2002) }\end{array}$ & $\begin{array}{l}\text { Constataram que risco, tamanho, composição dos ativos e crescimento } \\
\text { são fatores determinantes da estrutura de capital das empresas, enquanto } \\
\text { rentabilidade e tipo de capital não se mostraram relevantes para a forma } \\
\text { como as empresas se financiam. }\end{array}$ \\
\hline
\end{tabular}

FONTE - Elaborado pelos autores.

Na literatura internacional, Dickey e Piotroski (2001), analisando uma amostra de 400 empresas americanas, por meio de um estudo de evento com dados dos anos de 1970 a 1997, constataram que upgrades são insignificantes e downgrades são significantes. Firmas menores e com pior qualidade de crédito sofrem mais com um rebaixamento de rating. 


\section{METODOLOGIA}

Segundo a classificação apresentada por Gil (2008), esta pesquisa tem caráter descritivo, uma vez que envolve uma coleta de dados como observação sistemática para comparar e analisar dados do custo de capital de empresas brasileiras utilizando suas demonstrações financeiras anuais. Foi conduzida com enfoque quantitativo, utilizando para isso dados secundários obtidos da base de dados Economática ${ }^{\circledR}$ e do site do Banco Central do Brasil (Bacen). Ademais, é ex-post-facto, uma vez que se trata de dados já ocorridos no passado. Os testes estatísticos foram feitos no software Stata.

\section{Amostra e Período de Análise}

O período de análise desta pesquisa (2005 a 2015) foi escolhido em função das diversas alterações no rating soberano do Brasil, inclusive a obtenção e a perda do grau de investimento ocorrida em 2008 e 2015, respectivamente.

O Quadro 4 apresenta a amostra de empresas analisadas. Os critérios de seleção foram: (a) ser companhia brasileira listada na BM\&FBOVESPA; e, (b) possuir ADRs listados na Bolsa de Nova York e, ou NASDAQ desde 2005. Apenas 20 empresas atenderam a este segundo critério, com destaque para o fato de que, 12 figuram no Dow Jones Brazil Titans ADR Index (BR 20), mais conhecido como BR TITANS 20, calculado desde 2004, composto pelas empresas brasileiras de maior liquidez e com maior volume de negócios nas duas bolsas. Assim, as empresas analisadas contam com maior visibilidade no mercado internacional, sendo, portanto, mais sensíveis às alterações de rating soberano.

Quadro 4: Amostra Analisada

\begin{tabular}{|c|c|c|c|c|c|}
\hline $\mathbf{N}^{\mathbf{0}}$ & Empresa & Setor & $\mathbf{N}^{\mathbf{0}}$ & Empresa & Setor \\
\hline 1 & AES Tietê & Elétrico & 11 & Klabin & Papel e Celulose \\
\hline 2 & AmBev & Bebidas & 12 & Oi & Telefonia \\
\hline 3 & Braskem & Petroquímico & 13 & Pão de Açúcar & Petroleiro \\
\hline 4 & BRF Foods & Alimentos & 14 & Petrobras & Construção Civil \\
\hline 5 & Cemig & Elétrico & 15 & Rossi Residencial & Saneamento / Água \\
\hline 6 & CESP & Elétrico & 16 & Sabesp & Telefonia \\
\hline 7 & CSN & Siderúrgico & 17 & TIM Part. & Elétrico \\
\hline 8 & Embraer & Ind. Aérea & 18 & Tractebel Energia & Siderúrgico \\
\hline 9 & Gerdau & Siderúrgico & 19 & Usiminas & Mineração \\
\hline 10 & lochpe Maxion & Automotiva & 20 & Vale & \\
\hline
\end{tabular}

FONTE - Elaborado pelos autores. 


\section{Variáveis e Hipóteses de Pesquisa}

Para o cálculo do custo de capital (médio) de terceiros $(K d)$, foi utilizada equação 4 :

$$
K d=\frac{\text { Despesas Financeiras }}{\text { Dívida Onerosa Total }} \cdot(1-T)
$$

Os dados das despesas financeiras e endividamento total (passivo oneroso curto prazo + passivo oneroso longo prazo) foram extraídos da Demonstração de Resultado do Exercício e do Balanço Patrimonial, respectivamente, encerrados no final dos exercícios 2005 a 2015 das empresas analisadas. A alíquota de imposto ( $T$ ) utilizada foi de $34 \%$, que resulta da combinação de $15 \%$ de Imposto de Renda e também $10 \%$ sobre o que exceder R $\$ 240$ mil de faturamento, somado a 9\% de CSLL (Contribuição Social sobre Lucro Líquido).

Para o cálculo do custo de capital próprio (Ke) foi utilizada o CAPM global, descrito Assaf Neto (2014), que considera indicadores subordinados aos mercados financeiros globalizados que costumam oferecer maior liquidez e menor volatilidade das séries históricas. Em geral, é adotado como benchmarking o mercado acionário norte-americano, acrescido do indicador RISCObr - EMBI+ (Emerging Markets Bonds Index Plus), que indica na prática a diferença entre a taxa de juros exigida na precificação do título público brasileiro e a taxa de juros dos títulos emitidos pelo tesouro norte-americano, admitidos como de menor risco, conforme equação 5:

$$
K e=\left[R_{f}+\beta .\left(R_{m}-R_{f}\right)+R I S C O b r\right] .(1+\text { Dif.Inf } B R \times E U A)
$$

Na qual:

- taxa livre de risco $\left(R_{f}\right)$ : média dos títulos públicos de 10 anos emitidos pelo governo americano ( $T$ Bonds: treasury bonds), extraída do site http://pages.stern.nyu.edu/.

- coeficiente beta ( $\beta$ ): calculado a partir de dados mensais (históricos) dos cinco anos precedentes à análise, a partir dos retornos de cada ação e do lbovespa (proxy da carteira de mercado), conforme equação 2;

- retorno da carteira de mercado $(\mathrm{Rm})$ : média das taxas de rentabilidade do mercado de ações norteamericano, utilizando a média de retorno anual do indicador $S \& P 500$ dos últimos 50 anos extraída do site http://pages.stern.nyu.edu/.

- risco país (RISCObr): EMBI+, que expressa o risco de crédito a que investidores estrangeiros estão submetidos quando investem em determinado país. É calculado pelo Banco J.P. Morgan, e corresponde à média ponderada dos prêmios pagos por títulos brasileiros em relação a papéis de prazo equivalente do Tesouro dos Estados Unidos, tidos como os de menor risco do mundo (COPELAND, KOLLER e MURRIN, 2002).

- diferencial da inflação brasileira sobre a inflação americana (Dif. Inf $B R \times E U A$ ) devido à utilização de dados de mercado americano, assim como a taxa livre de risco também deste país, deve-se somar o diferencial de inflação entre o Brasil e Estados Unidos, adequando o custo de capital próprio a realidade do mercado brasileiro. Para a inflação americana, foi utilizado o índice IPC anual, calculado 
pelo departamento de estatísticas do trabalho americano e no Brasil, sendo utilizado o IPCA anual calculado pelo IBGE (Instituto Brasileiro de Geografia e Estatística) para o mercado brasileiro.

A Tabela 1 apresenta os dados utilizados no cálculo do Ke.

Tabela 1: Dados Utilizados no Cálculo do Ke

\begin{tabular}{ccccc}
\hline Ano & $\begin{array}{c}\text { Taxa livre de } \\
\text { Risco (Rf) }\end{array}$ & $\begin{array}{c}\text { Prêmio de } \\
\text { Risco } \\
\text { (Rm - Rf) }\end{array}$ & $\begin{array}{c}\text { Risco } \\
\text { Brasil } \\
\text { (EMBI+) }\end{array}$ & $\begin{array}{c}\text { Diferencial de } \\
\text { Inflação }\end{array}$ \\
\hline 2005 & $4,39 \%$ & $4,80 \%$ & $3,11 \%$ & $2,29 \%$ \\
2006 & $4,70 \%$ & $4,91 \%$ & $1,92 \%$ & $-0,06 \%$ \\
2007 & $4,02 \%$ & $4,79 \%$ & $2,21 \%$ & $1,65 \%$ \\
2008 & $2,21 \%$ & $3,88 \%$ & $4,28 \%$ & $2,10 \%$ \\
2009 & $3,84 \%$ & $4,29 \%$ & $1,92 \%$ & $4,71 \%$ \\
2010 & $3,29 \%$ & $4,31 \%$ & $1,89 \%$ & $4,30 \%$ \\
2011 & $1,88 \%$ & $4,10 \%$ & $2,08 \%$ & $3,30 \%$ \\
2012 & $1,76 \%$ & $4,20 \%$ & $1,42 \%$ & $3,73 \%$ \\
2013 & $3,04 \%$ & $4,62 \%$ & $2,24 \%$ & $4,41 \%$ \\
2014 & $2,17 \%$ & $4,60 \%$ & $2,59 \%$ & $4,81 \%$ \\
2015 & $2,27 \%$ & $4,54 \%$ & $5,23 \%$ & $10,57 \%$ \\
\hline
\end{tabular}

FONTE - Elaborado pelos autores com dados extraídos de: http://pages.stern.nyu.edu/ e http://www.ipeadata.gov.br

Após o cálculo do custo de capital próprio e custo de capital de terceiros, procedeu-se ao cálculo do WACC, conforme equação 3 , que reflete a ponderação do custo da dívida e o custo do capital próprio na proporção de sua participação na estrutura de capital da empresa.

No modelo testado, além das variáveis dependentes acima, foram utilizadas duas variáveis de controle, ligadas a fatores específicos das empresas (tamanho e alavancagem). A variável utilizada para medir o tamanho da empresa foi o logaritmo do ativo total. A proxy da alavancagem foi calculada pela divisão da dívida onerosa total sobre o ativo total.

Além dessas variáveis ligadas a fatores internos das empresas, o modelo contemplou também a variação das seguintes variáveis macroeconômicas: CDI, IPCA, PIB, Risco Brasil (EMBI+), Câmbio e uma variável dummy que sinaliza o comportamento do rating soberano da economia brasileira. 
Partindo-se da expectativa de que a obtenção do grau de investimento terá um efeito negativo no custo de capital das empresas, foram testadas as seguintes hipóteses:

Hipótese 1: a elevação do rating soberano do Brasil possui uma associação negativa com o custo do capital de terceiros, visto que a melhora na situação econômico-financeira das empresas leva os credores a exigir um retorno menor nos empréstimos efetuados, reduzindo desta forma o custo de capital de terceiros;

Hipótese 2: a elevação no rating soberano do Brasil possui uma associação negativa com o custo de capital próprio das empresas brasileiras;

Hipótese 3: a elevação do rating soberano do Brasil possui uma associação negativa com o custo do capital das empresas (WACC);

\section{Modelo Econométrico}

$\mathrm{Na}$ análise empírica foi utilizado um modelo de regressão múltipla com dados em painel, que segundo Greene (2011) consiste em uma série de tempo para cada membro do corte transversal do conjunto de dados, pode-se interpretar que são conjuntos de dados nos quais as mesmas unidades de corte transversal são acompanhadas ao longo do tempo.

Neste modelo, as variáveis dependentes foram custo de capital de terceiros $(K d)$, custo de capital próprio $(K e)$, custo de capital médio ponderado (WACC). Além disso, o modelo contemplou duas variáveis de controle (tamanho da empresa e grau de endividamento), cinco variáveis macroeconômicas (CDI, IPCA, PIB, $E M B I+$ e Câmbio), além de uma variável dummy que sinaliza o comportamento do rating soberano da economia brasileira.

Como o número de empresas é reduzido, ou seja, o $i$ da equação 1 é pequeno (20 empresas), optouse neste trabalho por utilizar o modelo de painel dinâmico, proposto por Arellano e Bond (1991), que por ser estimado pelo método dos momentos generalizados (MMG), ou seja, endógeno por construção, incorpora a variável dependente defasada entre as variáveis independentes. Em um modelo genérico de regressão múltipla:

$$
Y_{i t}=\beta_{0}+\sum_{j=1}^{k} \beta_{j} \cdot V I_{j i t}+\eta_{i t}+U_{i t}
$$

Na qual: $Y_{i t}$ : variável dependente; $\beta_{0}$ : intercepto / constante do modelo; $\sum_{j=1}^{k} \beta_{j} . V I_{j i t}$ : variável independente $j$, de um total de $k$ variáveis, medida para a empresa $i$ no ano $t ; \eta_{i t}+U_{i t}$ : compõem o termo de erro do modelo $\left(\varepsilon_{i t}\right)$. 
Nesta pesquisa foi utilizado o modelo para dados em painel (balanceado), uma vez que cada unidade de dados temporais apresenta o mesmo número de observações ao longo do período analisado. O modelo empírico estimado para identificar o impacto da alteração do rating soberano no custo de capital de empresas brasileiras foi:

$$
Y_{i t}=\beta_{1}+\beta_{2} \cdot L N A T_{i t}+\beta_{3} \cdot \text { Alav }_{i t}+\beta_{4} \cdot C D I_{t}+\beta_{5} \cdot I P C A_{t}+\beta_{6} \cdot P I B_{t}+\beta_{7} \cdot R B r_{t}+\beta_{8} \cdot \text { Câmbio }+\beta_{9} \cdot D_{-} \text {Rat t }_{t}+\varepsilon_{i t}
$$

Na qual: $\quad Y_{i t}$ : variáveis dependentes $\left(K d, K e\right.$ e WACC); $\beta_{1}=$ constante do modelo; LNAT e Alav: tamanho da empresa e alavancagem (variáveis de controle), CDI, IPCA, $\mathrm{PIB}, \mathrm{RBr}(E M B /+)$ e Câmbio: variáveis macroeconômicas; $D_{-}$Rat: variável dummy que sinaliza o comportamento do rating soberano da economia brasileira. Assume valor 0 quando o rating soberano é grau especulativo e 1, quando é grau de investimento; $\varepsilon_{i t}=$ termo de erro que capta o componente não sistemático, parcela de $Y_{i t}$ não explicada pelo modelo; $i$ representa a empresa e $t$ o respectivo exercício (com $t=1,2,3 \ldots 11)$.

Por se tratar de dados em painel com um número reduzido de empresas, a distribuição dos dados será assintótica no $i(i \rightarrow \infty)$. Nesta condição, segundo Arellano e Bond (1991), ocorrem dois problemas econométricos ao estimar o modelo acima por meio de técnicas de estimação tradicionais: 1. devido à presença dos efeitos não observáveis dos indivíduos, $\eta_{i t}$, juntamente com a variável dependente defasada, $\beta_{1} Y_{i t-1}$, no lado direito da equação. Nesse caso, omitir os efeitos fixos individuais no modelo dinâmico em painel torna os estimadores de mínimos quadrados ordinários (MQO) enviesados e inconsistentes. Entretanto, o estimador within groups, que corrige para presença de efeitos fixos, gera uma estimativa de $\beta_{1}$ enviesada para baixo em painéis com a dimensão temporal pequena; 2. devido à provável endogeneidade das variáveis explicativas. Nesse caso, endogeneidade no lado direito da equação (1) deve ser tratada para evitar um possível viés gerado por problema de simultaneidade.

Para corrigir este problema o modelo utiliza-se a estimação pelo método dos momentos generalizados (MMG), que usa um conjunto de condições de momentos (amostrais) como estimadores, podendo ter endongeneidade, não exigindo linearidade.

Tal método consiste na eliminação dos efeitos fixos através da primeira diferença da equação 6 , da seguinte forma:

$$
\Delta Y_{i t}=\beta_{1} \Delta Y_{i t-1}+\sum_{j=1}^{k} \beta_{j} . \Delta V I_{j i t}+\Delta \varepsilon_{i t}
$$

Na qual, para qualquer variável, $Y_{i t}, \Delta Y_{i t}=Y_{i t}-Y_{i t-1}$. Ou seja, a variação na variável dependente $\left(\Delta Y_{i t}\right)$ é explicada pela primeira diferença dela mesma e pela variação das variáveis dependentes do modelo $\left(\Delta V I_{j i t}\right)$. Na equação 8, a variação nas demais variáveis dependentes são instrumentos naturais porque são exógenas. Já a variação da variável dependente por diferença, causa um problema de endogenia no modelo. 
Como $\Delta Y_{i t}$ e $\Delta \varepsilon_{i t}$ são correlacionados na equação 8, os estimadores de MQO para seus coeficientes serão enviesados e inconsistentes, exigindo o uso de variáveis instrumentais para $\Delta Y_{i t-1}$. A metodologia proposta por Arellano e Bond (1991) e Arellano e Bover (1995) fornece um conjunto de instrumentos ótimos para corrigir este problema, ao identificar a defasagem adequada da variável dependente que deve ser utilizada no modelo.

As hipóteses adotadas na equação (3) implicam que as condições de momentos $E\left[\Delta Y_{, i t-s} \Delta \varepsilon_{i t}\right]=0$ , para $t=3,4,5, \ldots T$ e $s \geq 2$, são válidas. Baseado nesses momentos, Arellano e Bond (1991) sugerem empregar, para $t=3,4, \ldots T$ e $s \geq 2$, como instrumentos para equação (3).

Segundo Arellano e Bond (1991) e Baltagi (2005), as demais variáveis explicativas podem ser classificadas como: 1. estritamente exógena, se não é correlacionada com os termos de erro passados, presente e futuros; 2 . fracamente exógena, se é correlacionada apenas com valores passados do termo de erro e, c. endógena, se é correlacionada com os termos de erro passados, presente e futuros. No segundo caso, os valores da variável defasada em um ou mais períodos são instrumentos válidos na estimação da equação (3) e no último caso os valores defasados em dois ou mais períodos são instrumentos válidos na estimação dessa equação.

Assim, o modelo de Arellano-Bond, permite medir o efeito ao longo do tempo, da variável independente sobre a variável dependente, além de permitir observar a velocidade do ajuste do modelo por meio dos coeficientes das variáveis defasadas consideradas (ARELLANO e BOND, 1991; BALTAGI, 2005).

Os testes estatísticos foram realizados no software Stata 15. O nível de significância da análise dos coeficientes foi de $5 \%(p$-value $<0,05)$.

\section{RESULTADOS}

\section{Estatísticas descritivas das variáveis}

A Tabela 2 apresenta as estatísticas descritivas das variáveis dependentes e de controle: mínimo, máximo, média e desvio-padrão, da amostra analisada.

Tabela 2 - Estatística descritivas das variáveis dependentes e de controle

\begin{tabular}{ccccc}
\hline Variáveis & Média & Mínimo & Máximo & Desvio \\
\hline$K d$ & $10,64 \%$ & $5,94 \%$ & $66,67 \%$ & $9,39 \%$ \\
$K e$ & $9,16 \%$ & $3,99 \%$ & $17,48 \%$ & $2,61 \%$ \\
WACC & $9,14 \%$ & $1,40 \%$ & $23,37 \%$ & $2,92 \%$ \\
Tam & 16,923 & 13,422 & 20,618 & 1,299 \\
Alav & $31,42 \%$ & $2,98 \%$ & $70,47 \%$ & $12,82 \%$ \\
\hline \multicolumn{5}{c}{ Fonte - Elaborada pelos autores. }
\end{tabular}

Conforme se observa, em termos descritivos, por se tratar de empresas de grande porte (média do LNAT $=16,923$ ), com listagem de ações no mercado internacional, observa-se que o custo do capital próprio é baixo, pois em tese, são empresas de menor risco. Além disso, a forma de cálculo do Ke e as altas taxas de juros praticadas no mercado brasileiro explicam este ser menor do que o $K d$. A baixa alavancagem média 
das empresas, com apenas $31,42 \%$ dos ativos sendo bancados por capital de terceiros, reflete a preferência das grandes empresas em se financiar com recursos próprios, conforme discutem Barros, et al. (2000).

\section{Resultados do Modelo de Regressão}

De início destaca-se o fato de que a validade de um modelo de regressão múltipla com dados em painel dinâmico é confirmada quando a primeira defasagem das variáveis dependentes apresentar significância. Conforme se observa nas Tabelas 3, 4 e 5, apenas as variáveis $K d$ (a 10\%) e Ke (a 1\%) apresentaram significância estatística.

Tabela 3 - Resultados da regressão múltipla para a Variável $K d$

\begin{tabular}{c|cccc}
\hline Variável Dependente & Variáveis Explanatórias & Coeficientes & Erro Padrão & $\mathbf{p}>|\mathbf{z}|$ \\
\hline \multirow{6}{*}{ Kd } & Kd(L1.) & $\mathbf{0 , 1 4 9 9}$ & $\mathbf{0 , 0 8 0 7}$ & $\mathbf{0 , 0 6 3 ^ { * }}$ \\
& Tam & 0,0047 & 0,0217 & 0,830 \\
& Alav & $-0,1121$ & 0,0741 & 0,130 \\
CDI & 0,0137 & 0,0258 & 0,595 \\
& IPCA & $-0,2000$ & 0,0192 & 0,298 \\
& PIB & $-0,0924$ & 0,1741 & 0,596 \\
& RBr & 0,0113 & 0,0188 & 0,547 \\
& Câmbio & $\mathbf{0 , 1 0 1 5}$ & $\mathbf{0 , 0 4 3 8}$ & $\mathbf{0 , 0 2 0}$ \\
& D_Rat & $-0,1839$ & 0,0140 & 0,190 \\
& Constante & 0,0527 & 0,3587 & 0,883 \\
\hline
\end{tabular}

Nota: ${ }^{* * *},{ }^{* *},{ }^{*}$, denota significância a 1\%, 5\% e 10\%, respectivamente, $K d($ L1. $)=$ primeira defasagem da variável $K d$.

Prob > $\mathrm{Chi}^{2}-0,0000$

$\mathrm{N}^{\circ}$ Observações $=180$

Wald $\mathrm{Chi}^{2}(9)=71,09$

GMM-Type $=\mathrm{L}(2 /.) \cdot \mathrm{Kd}$

FONTE - Elaborada pelos autores.

A Tabela 3 apresenta o resultado para a variável dependente $K d$. Conforme se observa, apesar de não significante, a variável dummy que captura a oscilação do rating soberano do Brasil apresentou sinal negativo, conforme esperado, dando indícios de que a obtenção do grau de investimento contribuiu para a captação de recursos, por parte das empresas analisadas, a um custo menor. Este indício, conforme defendem Múrcia, Múrcia e Borba (2014), está em consonância com a lógica de que o custo de capital de terceiros se torna mais elevado na medida em que o rating se deteriora. Por essa razão, ele impacta igualmente as decisões dos gestores da empresa acerca de novos empréstimos e financiamentos, além de afetar diretamente os resultados em razão das despesas de juros altamente correlacionadas com a avaliação de crédito recebida.

Apesar da validade do modelo, apenas a variável câmbio apresentou significância estatística a 5\%, apresentando uma relação positiva com custo de capital de terceiros das empresas analisadas. Este resultado pode ser explicado pela elevação da cotação do dólar no período. Se for comparado o dólar de fechamento de 2007, ano no qual o Brasil ainda não detinha o grau de investimento contra 2014, obtém-se uma 
valorização de aproximadamente $49 \%$. Por se tratar de empresas que captam recursos no mercado internacional, com mais de $40 \%$ de dívidas em moeda estrangeira, essa valorização do câmbio contribui para a elevação do custo do endividamento.

Dessa forma, aparentemente as empresas se beneficiaram da melhora do rating soberano quanto à captação de empréstimos, porém, outros fatores afetaram de forma negativa este benefício.

A Tabela 4 apresenta os resultados do modelo para a variável $K e$, que apresentou os resultados mais consistentes desta pesquisa. Conforme mencionado acima, a significância da primeira defasagem da variável dependente (a $1 \%$ ), validando o modelo, associada ao sinal negativo da variável dummy que captura a oscilação do rating soberano do Brasil, não permite rejeitar a hipótese 2, sinalizando o benefício que as empresas brasileiras tiveram com a obtenção do grau de investimento, que resultou em um menor custo de capital próprio, que é a principal fonte de recursos utilizada pelas grandes empresas brasileiras, devido a diversos fatores apresentados em Barros, et al. (2000), refletindo o seu conservadorismo quanto à alavancagem. Segundo estes autores, o capital próprio representa em média $63 \%$ das fontes de recursos de financiamento das grandes empresas brasileiras, reforçando o benefício da melhora do rating soberano.

Tabela 4 - Resultados da regressão múltipla para a Variável Ke

\begin{tabular}{|c|c|c|c|c|}
\hline Variável Dependente & Variáveis Explanatórias & Coeficientes & Erro Padrão & $p>|z|$ \\
\hline \multirow{10}{*}{ Ke } & $\operatorname{Ke}(\mathrm{L} 1)$. & 0,6259 & 0,0959 & $0,000^{* * *}$ \\
\hline & Tam & 0,0092 & 0,0045 & $0,041^{* *}$ \\
\hline & Alav & 0,0121 & 0,0150 & 0,420 \\
\hline & CDI & $-0,0289$ & 0,0070 & $0,000 * * *$ \\
\hline & IPCA & 0,0046 & 0,0040 & 0,246 \\
\hline & PIB & $-0,2608$ & 0,0385 & $0,000^{* * *}$ \\
\hline & $\mathrm{RBr}$ & 0,0359 & 0,0043 & $0,000^{* * *}$ \\
\hline & Câmbio & $-0,0633$ & 0,0090 & $0,000 * * *$ \\
\hline & D_Rat & $-0,0065$ & 0,0034 & $0,055^{*}$ \\
\hline & Constante & $-0,1175$ & 0,0760 & 0,122 \\
\hline 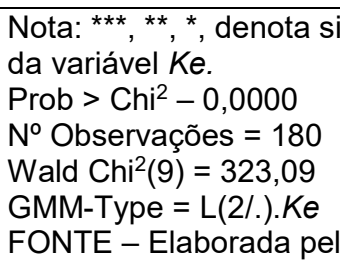 & nificância a 1\%, 5\% e 10\%, & spectivamente, & $e($ L1. $)=$ primeir & defasagem \\
\hline
\end{tabular}

Além disso, a variável tamanho (LNAT) apresentou significância estatística (relação positiva), assim como em Soares, Coutinho e Camargos (2012), e, quatro variáveis macroeconômicas, CDI, PIB e Câmbio relação negativa e risco país (EMBI+), relação positiva.

A Tabela 5 apresenta o resultado para a variável dependente WACC. Conforme se observa, apesar da não significância da primeira defasagem da variável dependente, a variável dummy que captura a oscilação do rating soberano do Brasil apresentou sinal negativo, conforme esperado, dando indícios de que a melhora do rating soberano do Brasil, passando de grau especulativo para grau de investimento, o efeito para a 
variável WACC foi negativa, assim, aparentemente, as empresas se beneficiaram de um menor custo de capital neste período.

Este indício se mostra relevante na perspectiva de que o rating é considerado o segundo atributo mais importante pelos chief finance officers (CFOs) na tomada de decisões sobre a política financeira da empresa (KANG e LIU, 2007).

Tabela 5 - Resultados da regressão múltipla para a Variável WACC

\begin{tabular}{ccccc}
\hline Variável Dependente & Variáveis Explanatórias & Coeficientes & Erro Padrão & $\mathbf{p}>\mathbf{z} \mid$ \\
\hline WACC(L1.) & $-0,0305$ & 0,0868 & 0,725 \\
LNAT & 0,0041 & 0,0089 & 0,645 \\
Alav & 0,0269 & 0,0310 & 0,386 \\
CDI & 0,0045 & 0,0112 & 0,687 \\
WACC & IPCA & $-0,0073$ & 0,0081 & 0,369 \\
& PIB & 0,0078 & 0,0715 & 0,913 \\
RBr & $\mathbf{0 , 0 1 6 2}$ & $\mathbf{0 , 0 0 8 0}$ & $\mathbf{0 , 0 4 2 ^ { * * }}$ \\
& Câmbio & $-0,0080$ & 0,0186 & 0,665 \\
D_Rat & $\mathbf{- 0 , 0 2 2 2}$ & $\mathbf{0 , 0 0 5 8}$ & $\mathbf{0 , 0 0 0}$ \\
& Constante & 0,0266 & 0,1484 & 0,858 \\
\hline
\end{tabular}

Nota: ${ }^{*} ;{ }^{* *} ;{ }^{* * *}$, denota significância a $1 \%, 5 \%$ e $10 \%$, respectivamente, $W A C C($ L1.) $=$ primeira defasagem da variável WACC.

Prob $>\mathrm{Chi}^{2}-0,0000$

$\mathrm{N}^{\circ}$ Observações $=180$

Wald $\mathrm{Chi}^{2}(9)=93,09$

GMM-Type $=\mathrm{L}(2 /$.$) . WACC$

FONTE - Elaborada pelos autores.

A variável de risco país (EMBI+) apresentou o sinal de positivo e significante a $5 \%$ com o WACC. Merece destaque o fato de que este indicador apresentou uma elevação de 102\% em 2015.

Enfim, cabe destacar que não foi encontrado na literatura nacional pesquisa com objetivo semelhante ao desta. Conforme destacam Gray, Mirkovic e Ragunathan (2006), em termos práticos, na visão das empresas, o rating possui grande importância prática, uma vez que impacta no custo da dívida da empresa, em sua estrutura de financiamento e até em sua capacidade de continuar negociando seus títulos. Pode-se dizer que em linhas gerais, os resultados obtidos nesta pesquisa atestam que o rating afeta o custo de capital (próprio) das empresas. 


\section{CONSIDERAÇÕES FINAIS}

Após a obtenção de grau de investimento de um rating soberano, o país se beneficia de diversas formas, principalmente quanto à redução de risco percebido pelos agentes estrangeiros e nacionais. Alguns dos benefícios que o país obtém é o maior nível de capital estrangeiro inserido no país que aumenta os investimentos na produção interna bruta, resultantes do maior nível de competitividade do país e de investimento, estabilidade de indicadores econômicos como taxa de juros, inflação e redução do custo financeiro para a obtenção de empréstimos nacionais e estrangeiros, no ponto de vista corporativo das empresas brasileiras e também do governo federal.

Este último benefício de redução de custo financeiro foi analisado neste trabalho sob o ponto de vista corporativo. O Brasil alcançou o grau de investimento em 2008 e em 2011 teve uma elevação em sua classificação de risco, atingindo assim sua maior nota, mas voltou à classificação de grau especulativo em 2015. Visando verificar se este benefício foi refletido nas companhias brasileiras foram calculados e analisados o custo de capital próprio $(K e)$, de terceiros $(K d)$ e total (WACC) de uma amostra de 20 empresas que possuem acesso também ao mercado norte-americano através de $A D R$ 's e apresentam alto nível de governança corporativa.

Os resultados encontrados nesta pesquisa sinalizam para uma redução quanto ao custo de capital das empresas brasileiras, com evidências para o custo do capital próprio, assim como mostram que as companhias aproveitaram este cenário vivenciado pelo país e aumentaram de forma significativa seus investimentos em novos projetos com objetivo de majoração de retorno.

Em síntese, pode se concluir que a obtenção do grau de investimento pelo Brasil está associada a uma redução do custo de capital (próprio) das empresas brasileiras. Consequentemente, esta redução, eleva o nível de investimentos das empresas e de forma inesperada foi destacado que as empresas ainda optam por um maior nível de capital próprio do que capital de terceiros em sua estrutura de fontes de financiamentos.

Destaca-se que a contribuição desta pesquisa está na identificação de que há uma relação negativa entre melhora da classificação do risco soberano e o custo de capital de empresas brasileiras, abrindo uma nova frente para os estudos sobre o rating.

Por fim, merece registro as limitações deste estudo. A primeira delas seria o número pequeno de empresas da amostra que tinham dados disponíveis no período analisado, que limita seu poder de generalização, fato atenuado pelo modelo econométrico utilizado. Como sugestão de pesquisas futuras podese analisar o impacto de alterações no rating corporativo sobre o custo de capital da empresa.

\section{REFERÊNCIAS}

ALMEIDA, H. Alterações no rating soberano e o impacto nos retornos do Índice Bovespa e spread do risco país. Dissertação (Mestrado em Finanças e Economia do Setor Público) - Universidade de Santa Catarina, Santa Catarina, 2010.

ALTMAN, E., CAOUETTE, J.; NARAYANAN, P. Managing credit risk: the next great financial challenge. Chichester: John Wiley \& Sons, Inc., 1998.

ARELLANO, M.; BOND, S. Some tests of specification for panel data: Monte Carlo evidence and an application to employment equations. Review of Economic Studies, v.58, n. 2, p.277-297, 1991. 
ARELLANO, M.; BOVER, O. Another look at the instrumental variable estimation of error-components models. Journal of Econometrics, v. 68, p. 29-51. 1995.

ASSAF NETO, A. Mercado financeiro. 13. ed., São Paulo: Atlas, 2014.

ASSAF NETO, A.; LIMA, F.G.; ARAÚJO, A.M.P. Uma proposta metodológica para o cálculo do custo de capital no Brasil. Revista Administração: São Paulo, v.43, n.1, p.72-83, 2008.

BALTAGI, B. H. Econometric analysis of panel data. Chichester: Wiley, 2005.

BARROS, J. R. M.; et al. Desafios e oportunidades para o mercado de capitais brasileiro. São Paulo: Bovespa, Jul. 2000.

BRITO, G.; CORRAR, L.; BATISTELLA, F. Fatores determinantes da estrutura de capital das maiores empresas que atuam no Brasil. Revista Contabilidade \& Finanças, São Paulo, v.2, n.43, USP, 2007.

BRITO, G.; ASSAF NETO, A.; CORRAR, L. Sistema de classificação de risco de crédito: uma aplicação a companhia abertas no Brasil. Revista Contabilidade \& Finanças, São Paulo, v.20, n. 51, USP, 2009.

CAVALCANTE, F.; MISUMI, J.Y.; RUDGE, L.F. Mercado de capitais: o que é, como funciona. 7. ed. Rio de Janeiro: Campus, 2009.

CHAN, P.T.; EDWARDS, V.; WALTER, T. The information content of Australian credit ratings: a comparison between subscription and non-subscription-based credit rating agencies. Economic Systems, v.33, n.1, p.22-44, 2009.

COPELAND, T.; KOLLER, T.; MURRIN, J. Avaliação de empresas: valuation - calculando e gerenciado o valor das empresas. São Paulo: Makron Books, 2002.

CREIGHTON, A.; GOWER, L.; RICHARDS, A.J. The impact of rating changes in Australian financial markets. PacificBasin Finance Journal, v.15, n.1, p.1-17, 2007.

DAMASCENO, D.; ARTES, R.; MINARDI, A. Determinação de rating de crédito de empresas brasileiras com a utilização de índices contábeis. Revista Administração: São Paulo, v.43, n.4, p.344-355, 2008.

DAMODARAN, A. Finanças corporativas. Porto Alegre: Bookman, 2004.

DICKEY, I.; PIOTROSKI, J. The long run stock returns following bond ratings changes. The Journal of Finance, v. $56, \mathrm{n}$. $1,2001$.

EID JR. W. Custo e estrutura de capital: o comportamento das empresas brasileiras. Revista de Administração de Empresas, v.36, n.4, p.51-59, 1996.

GIL, A. C. Métodos e técnicas de pesquisa social. 6. ed., São Paulo: Atlas, 2008.

GREENE, W. H. Econometric analysis. 7th ed. New Jersey: Prentice-Hall. 2011.

GRAY, S.; MIRKOVIC, A.; RAGUNATHAN, V. The determinants of credit ratings: Australian evidence. Australian Journal of Management, v.31, n.2, p.333-354, 2006.

JORION, P.; LIU, Z.; SHI, C. Informational effects of regulation FD: evidence from rating agencies. Journal of Financial Economics, v.76, n.2, p.309-330, 2005.

KANG, Q.; LIU, Q. Credit rating changes and CEO incentives. [S.I]: Social Science Research Network. Fev. 2007, Working Paper. Disponível em: <http://ssrn.com/abstract=971277>. Acesso em: 24 set. 2016.

KLIGER, D.; SARIG, O. The information value of bond ratings. The Journal of Finance, v.55, n.6, p.2879-2902, 2000.

KLOTZLE, M. C.; et al. Impactos do rating soberano brasileiro sobre ações de estatais. Revista da Faculdade de Administração e Economia, v. 8, n. 1, p. 209-229, 2016.

MOODY'S INVESTOR SERVICE, Rating methodology. New York City, McGraw Hill, 1999.

MURCIA, F.C.S.; MURCIA, D.R.; BORBA, J.A. Rating de crédito corporativo: revisão da literatura e oportunidades para pesquisa no cenário brasileiro. Revista de Economia e Administração, v.13, n.1, p.54-96, 2014

POON, W.; CHAN, K. An empirical examination of the informational content of credit ratings in China. Journal of Business Research, v.61, n.7, p.790-797, 2008.

ROSS, S.A.; WESTERFIELD, R.W.; JAFFE, J.F.; LAMB, R. Administração financeira. São Paulo: Bookman, 2015.

SCHUERMANN, T.; JAFRY, Y. Measurement and estimation of credit migration matrices. Center for Financial Institutions Working Papers 03-08, Wharton School Center for Financial Institutions, University of Pennsylvania, 2003.

SILVA, J. P. Gestão e análise de risco de crédito. São Paulo: Atlas, 2008.

SOARES, G.O.G.; COUTINHO, E.; CAMARGOS, M.A. Determinantes do rating de crédito de companhias brasileiras. Revista Contabilidade Vista \& Revista, v.23, n.3, p. 109-43, 2012.

STANDARD \& POOR'S. Fundamentals of corporate credit analysis. New York City, McGraw Hill, 2004. 